\title{
Radial Precision Printing for the Textile Industry Controlled by Fuzzy Logic
}

\author{
Juan José Encinas C. and Mario Chauca
}

\begin{abstract}
The objective of this project is to optimize the stamping process in the industry dedicated to the textile sector using fuzzy control. For this, an automated system capable of carrying out the mentioned process will be implemented in such a way that the stamping is done in an automated way and in this way reduce costs in the textile industry. This will have an alternator mechanism in which prints of various colors will be made on the fabrics, four levers that will keep the screen printing of different colors and image, and the motors will be controlled so that the stamping can be synchronized.
\end{abstract}

Index Terms-Automated, serigraphy, mechatronics, optimize, stamping.

\section{INTRODUCTION}

Automation in production systems is defined as a technology related to the application of mechanical and electronic systems integrated with computerized systems for operation and control of production [1].

Modern automated manufacturing systems operate in the factory on the raw material where they perform operations, such as processing, assembly, inspection or handling of materials. And these automated operations are performed with a low level of human participation compared to the corresponding manual process [2].

In order to achieve process automation with Mechatronics technology, a thorough analysis must first be carried out of the type of equipment used in the process, of the operations that can be automated, of the working conditions in which the activities are carried out, and mainly the conditions ergonomic and anthropometric of workers in their humanmachine relationship, to determine the physical and mental effects that affect operators due to the working conditions to which they are subjected, which will lead us to determine the processes in which it is required some degree of automation.

The case in question is oriented towards the analysis and redesign of a manual device called octopus of 6-arm screen printing, in order to plan its automation with the use of Mechatronics technology. Once the dynamic aspects (effort, repetitiveness) were analyzed, a study was made regarding the entities and opportunities for automation with the ultimate aim of improving the working conditions of the operators.

The design of devices for processes, although it goes through stages of ergonomic design, is rarely oriented

Manuscript received November 22, 2018; revised March 1, 2019.

The authors are with the Ricardo Palma University - Mechatronics Engineering, Av. Benavides 5440-Santiago de Surco-Lima 33, Perú (e-mail: encinas_2010@hotmail.com, mario.chauca@urp.edu.pe). towards physiognomic patterns typical of the community that adopts them [3].

This system of radial precision stamping for the textile industry controlled by fuzzy logic consists of three main parts, which are the mechanical, electronic and programming part, making this system a new technological development for the environment of the textile industry, since that today would innovate and reduce costs.

The process of artisanal printing requires both tools, as well as an appropriate procedure depending on the time.

The steps to follow are as follows: first the fabric is positioned without any type of wrinkle, then the image of the silkscreen to be used is selected, then the colors to be used are chosen, then all the serigraphs to be used for printing are placed an image of several colors according to what you want to obtain, then wait for the fabric to be ironed and ready for the warehouse [4].

This system aims to design and implement an industrial prototype that makes the stamping on the fabric, according to the color parameters, having six high-speed arms in its mechanism automatically, sequentially and at a low cost. The project consists of integrating the elements of an industrial classification system with an image processing software to perform the analysis of large quantities of fabric and separate the fabrics according to the color determined by the user.

In the first instance it is intended to design a system that is capable of stamping large quantities of fabrics and at the same time that can control the desired color, then those that are looking for is to select the screen printing and at the same time can control the rotation of the arms.

Currently there are machines capable of separating up to 8 colors of screen printing, but at an excessively expensive price and that do not adapt to the medium production sectors, which in our country are the largest part of entrepreneurs dedicated to the development and production in the textile industry. The design will be made around the needs of the Peruvian market.

All this is done since it is a more common method for printing, since it requires pressing the mechanical arm of the screen printing on the fabric and the content of the dye solution. It is usually a combination of water and dye. All this can be done with a serigraphic printer or silk screen octopus, as shown in Fig. 1 [5].

As a team to use, we will have:

- Silkscreen octopus

- Screen with aluminum or wood frame

- Aluminum or wood scraper for application of inks.

The great strength that it handles and its versatility makes that we make the most of it, obtaining good results, allowing the desired color pattern to penetrate the threads. The 
process will be carried out at high temperature, in general it is intended to improve the conditions of migration and equalization of the dyes. With the process can be stamped at high temperatures, then down to the drying temperatures of these dyes [6].

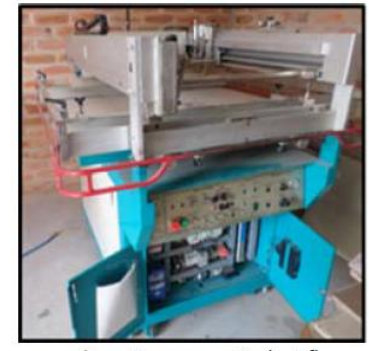

a) Impresora Serigráfica

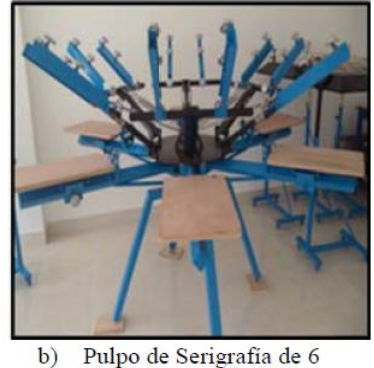

b) Pulpo de Serigrafía de 6

Fig. 1. Screen printing machines.

Fuzzy logic is a fair mathematical where we have sought to give an answer to those problems where decision making is very similar to the way of reasoning of human beings and bases its foundations on the experience of the systems. Its application in the areas of automatic control has been of great importance, especially in the control of processes where the dynamics of the system is non-linear, for example, the setting up of an inverted pendulum system, oscillatory systems such as LC circuits or spring mass systems, etc.

For the design of the fuzzy controller, two different approaches were taken into account (P1 and P2), that is, two different rule bases and sets were defined to show that these controllers can be carried out in many ways and that some solutions may be better than others, you can also see that the definition of more or less sets significantly affects the behavior of the system [7].

With this you have the fuzzy controller design, you must simulate it using the connection diagram in Simulink shown in Fig. 2 below:

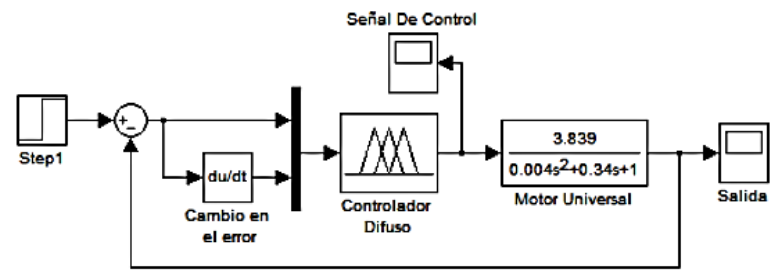

Fig. 2. Closed loop system using the fuzzy controller [8].

Para to be able to subject the fabric to this process, it is necessary to know the properties of the fibers.

The properties of the fibers are given as a function of their external and internal natural structure, chemical composition, in addition to the fact that the sets of these contribute to the properties of the fabric. But there are a number of characteristics that are common to most textile fibers [9]. One of the most important characteristics in this process is the elasticity and elongation of the yarn. The elasticity is the quality that allows the fiber to recover a certain length, when it ceases to be subjected to the action of the pulling force, where the percentage of recovered length is expressed with respect to its stretch [10].

$$
\left(\frac{B-R}{B-l}\right) \cdot 100 \quad \text { para } \quad R \neq l
$$

where:

\section{$I=$ Original length}

$B=$ Length of the fiber at the moment of breaking

$R=$ Length that retains the fiber after applying the traction

The elongation expresses the length acquired by the fiber that has been subjected to a force in the direction of traction at the moment of rupture. It is described as the percentage of the length difference in relation inversely proportional to the original extension [10].

$$
\left(\frac{B-l}{l}\right) \cdot 100
$$

Stamping is leaving written or drawn something on fabric, leather, paper or other material exerting pressure on the mold that contains it, making a difference in the clothes by moving the colors of nature to the objects of your daily life [11].

Screen printing is very modern in its application if we compare it with other printing techniques. Also the serigraphy as a technique is of great importance to facilitate the current pictorial languages and their multiplicity, but it is also important as a pictorial language. In addition, the rapidity of events at the present time in the field of artistic events, found in screen printing a great ally to facilitate these languages. As shown in Fig. 3 [12].

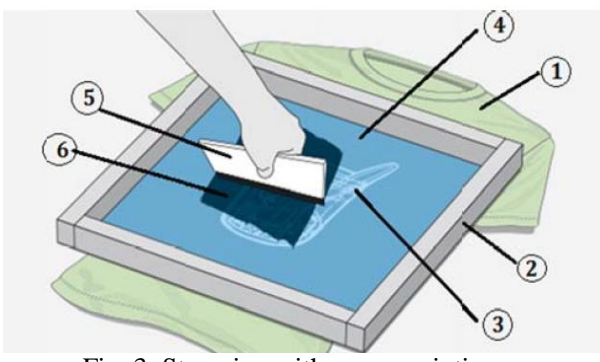

Fig. 3. Stamping with screen printing.

1) Printing to print

2) Wooden frame

3) Image or design to stamp

4) Nylon or polyester mesh

5) Scraper

6) Screen printing ink

By making a brief comparison of PID controllers and fuzzy logic we can say that:

PID controllers are the best known and most commonly used for the control of industrial processes and in its 60 years of existence there are many applications where they have been used, for example, in the temperature control of a boiler to the control of an AC motor [13].

Despite being so used and known, there has always been the problem of the applicability of this controller in processes that are non-linear in nature since the dynamics under which a PID controller works is for the control of industrial processes and that is where it enters at stake the use of intelligent control with fuzzy logic. [14].

Fuzzy logic is a fair mathematical where we have sought to give an answer to those problems where decision making is very similar to the way of reasoning of human beings and bases its foundations on the experience of the systems [15].

Its application in the areas of automatic control has been 
of great importance, especially in the control of processes where the dynamics of the system is non-linear, for example, the setting up of an inverted pendulum system, oscillatory systems such as LC circuits or spring mass systems, etc. [16].

In Peru, a great source of economic growth is linked to the textile industry.

Currently in Peru to counteract the increased competition in the main destination markets, companies would continue to diversify their export destinations and promoting the commercialization of products with their own brands, placing part of their production in the local market, taking advantage of the expansion of the retail segment. As shown in Fig. 4. [17].

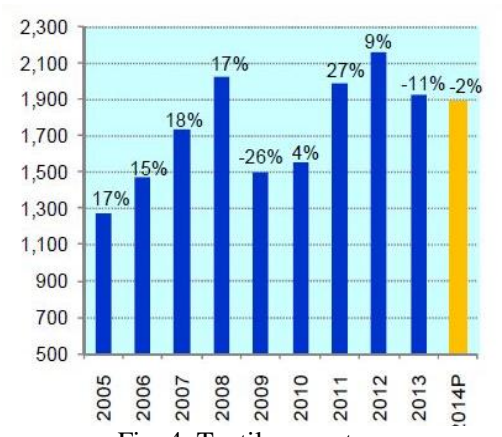

Fig. 4. Textile exports.

\section{DEVELOPMENT}

This project consists of designing and implementing an automated system to make the printing of fabrics.

Then, the most important stages that have been taken into account for the realization of this project have been divided into four sections.

\section{A. Design}

The design consists of three parts:

- Four metal arms that contain the screen printing with the image and color chosen by the user, one color in each silk screen. In addition, each of these must have a mechanical design that controls the precision of the screen print to the table or base where the fabric will be where the printing process will be made, according to what is required.

- A main and wide plate, where the painting will be dried and the fabrics stamped. This should work as a washing machine system, that is, it should rotate so that the colors of the screen printing are stamped and a synchronized and precise stamping is obtained, for the quality of the stamping.

- A DC motor will be placed in the lower and central part of the metal arms, in such a way that, once the stamping process is finished, it will activate and cause the paint to drain through the conduit where it is and leave the frame of the empty serigraphy. This will facilitate the removal of the silk screen and thus not cause damage to the fabric. The development of the ideal mechanism is given by an optimal design for the performance of this system, thus having to couple a direct current motor to perform the rotation of the arm, guaranteeing a total work of stamping.

DC motors are the most versatile in the industry. Its easy position, stop and speed control have made it one of the best options in process control and automation applications. [18] The dynamics of the actuator of a DC motor are presented. Consider the diagram in Fig. 5.

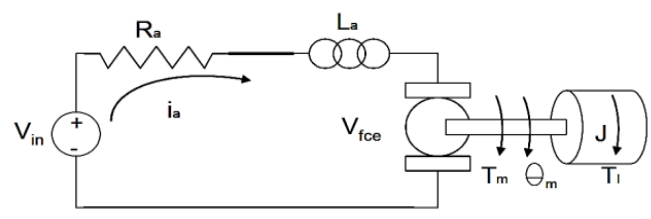

Fig. 5. DC motor [19]

The differential equation of the motor controlled by the armature current is given by:

$$
L_{a} \frac{d i_{a}}{d t}+i_{a} R_{a}=V_{i n}-V_{f c e}
$$

where $V_{\text {in }}$ is the input voltage in Volts, $i_{a}$ is the armature current in Amperes, $\mathrm{Ra}$ is the armature resistance in Ohms.

The electric time constant $L_{a} / R_{a}$ is much smaller than the mechanical time constant $\mathrm{J} / \mathrm{Bm}$, which allows to reduce the order of the model in the dynamics of the actuator. The differential equation of the engine model is given by:

$$
\frac{R_{a} J}{K_{m} K_{g}} \ddot{\theta}+\left(\frac{R_{a} B_{m}}{K_{m} K_{g}}+K_{m}\right) \dot{\theta}=V_{i n}
$$

For the design of the pneumatic system, it is necessary to establish the quantity of actuators and necessary elements, for the stamping process. With Fig. 6, we proceed to the selection of each component.

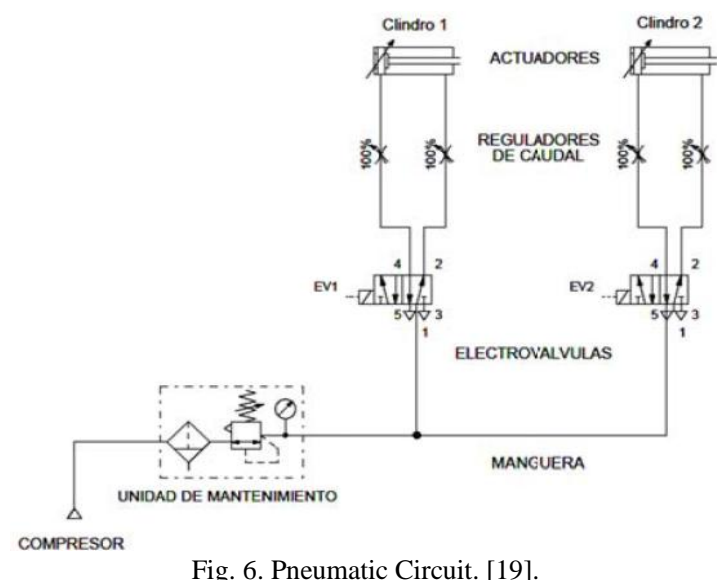

Fig. 6. Pneumatic Circuit. [19].

\section{Cylinder selection}

The main variables to consider in the selection of the pneumatic cylinders are the cylinder force, the load, the air consumption and the piston speed [17].

The force of the cylinder is a function of the diameter of the cylinder, of the air pressure and friction of the plunger, which depends on the speed of the plunger and which is taken at the moment of starting. The force that the air exerts on the piston is

$$
F=P * A
$$

The pressure required to carry out the pressing process is:

$$
P=11441.124 \mathrm{~N} / \mathrm{m}^{2}
$$

With the dimensions of the plate of $0.5 \times 0.4 \mathrm{~m}$, we 
obtain an area of $0.2 \mathrm{~m}^{2}$.

Applying the formula of equation 3 force on the plate is:

$$
F=2288,225 \mathrm{~N}
$$

With which you can determine the area of the cylinder working at the maximum pressure of the compressor that is 8 Bar. Obtaining the clearance of the equation 3.

$$
A=0.00286 \mathrm{~m}^{2}
$$

With the area of the cylinder, it is necessary to consider that the selection of the cylinder depends on the diameter of the plunger, the same that is calculated by means of the following equation.

$$
F \text { advance }=P \text { air } * \text { pi } D 2 / 40
$$

With:

$F$ advance $=$ Piston advance force $[\mathrm{N}]$

$P$ air $=$ Air pressure $[$ Bar $]$

$D=$ Cylinder diameter $[\mathrm{mm}]$

\section{B. Programming}

Next, in Fig. 7 the flow diagram corresponding to the beginning of the process and a fragment of the programming using the Arduino Software, for the control of the DC motors, corresponding to the stage where the arms will rotate in a synchronized manner is presented. Get an accurate print of the fabrics.

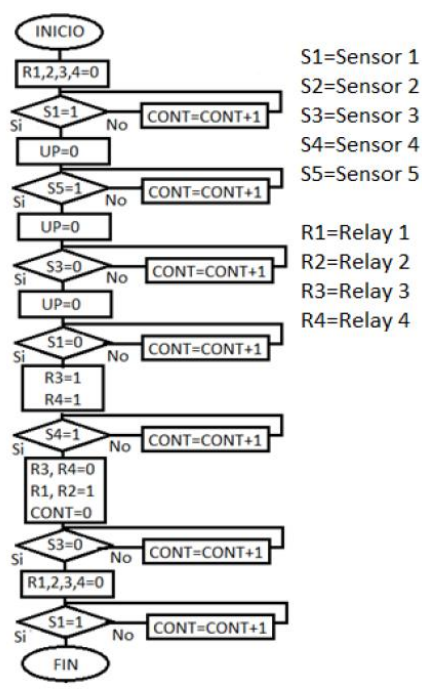

Fig. 7. System flow diagram.

The Arduino Mega was used as a module:

\#include<Servo.h>

Servo ESC; //Crear un objeto de clase servo int vel = 1000; //amplitud del pulso

void $\operatorname{setup}()$

\{

//Asignar un pin al ESC

ESC.attach(9);

//Activar el ESC

ESC.writeMicroseconds(1000); //1000 = 1ms

//Cambiar el 1000 anterior por $2000 \mathrm{si}$

//el ESC se activa con un pulso de $2 \mathrm{~ms}$

delay(5000); //Esperar 5 segundos para hacer la activacion

$/ /$ Iniciar puerto serial

Serial.begin(9600);

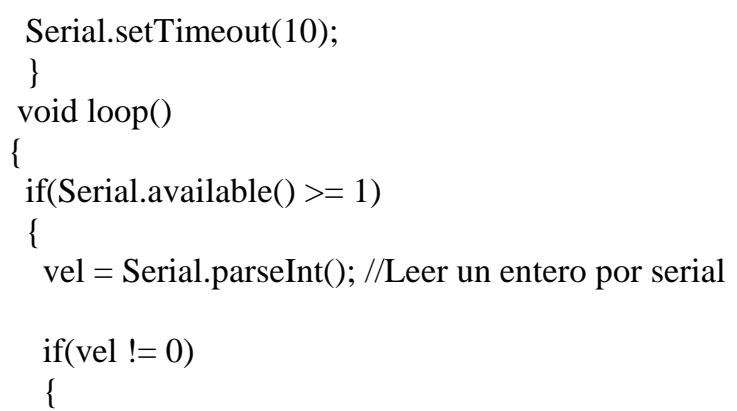

ESC.writeMicroseconds(vel); //Generar un pulso con el numero recibido

\}

\}

\}

C. Tests

To verify that the implementation of our project works, it is necessary to carry out tests.

1) Check if the programming allows the whole system to comply with the required action. That is, tests will be done with each of the mechanical arms and with the motor, one by one and as a whole, in such a way that we make sure that the function is indicated.

2) Verify that the design and structure of our system is stable and that it resists the physical conditions to which it is submitted.

3) To verify if the printing of the fabric was successful, a series of tests will be carried out where the PWM signal that will control the movement of the motor will be varied, this in order to obtain a synchronized and correct mixture.

\section{RESULTS}

Next, in Table I, the relationship of the cylinder force for different pressures is presented, where it can be seen that as the pressure increases the strength of the cylinder also increases.

TABLE I: FORCE OF THE CYLINDER FOR DIFFERENT PRESSURES

\begin{tabular}{|c|c|c|}
\hline Pressure (Bar) & Diameter Cylinder $(\mathrm{mm})$ & Force $(\mathrm{N})$ \\
\hline 4 & 63 & 1246,90 \\
\hline 5 & 63 & 1558,63 \\
\hline 6 & 63 & 1870,35 \\
\hline 7 & 63 & 2182,08 \\
\hline
\end{tabular}

Next, in Table II, the relation of the amount of ink with respect to the time of the mechanical arm is presented, where the time of movement of the mechanical arm can be observed so that it deposits a certain amount of ink for the printing of the screen printing.

TABLE II: QUANTITY OF TINT WITH RESPECT TO THE MECHANICAL ARM

\begin{tabular}{|l|l|l|}
\hline $100 \mathrm{ml}$ & $200 \mathrm{ml}$ & $300 \mathrm{ml}$ \\
\hline $1 \mathrm{~min}$ & $1,5 \mathrm{~min}$ & $2 \mathrm{~min}$ \\
\hline
\end{tabular}

Next, in Table III, the relation of the printing time according to the rotation of the image is presented, where the position of the mechanical arm is observed to make the printing of the image with the screen printing in a certain time. 
TABLE III: TIME OF PRINTING ACCORDING TO THE TURN OF THE IMAGE

\begin{tabular}{|l|l|l|}
\hline 90 degrees & 180 degrees & 270 degrees \\
\hline $10 \mathrm{~min}$ & $10 \mathrm{~min}$ & $10 \mathrm{~min}$ \\
\hline
\end{tabular}

\section{CONCLUSIONS}

- This type of automated system allows productivity standards to be maximized within the textile industry, as it gives us efficiency in terms of time and saving of inputs such as water and dyes.

- To obtain an optimal stamping the water together with the dye must be at $100{ }^{\circ} \mathrm{C}$, and this temperature must be maintained for 35-40 minutes while the main container circulates smoothly and the paint does not dry.

- The relation of cloth to stamp and water for painting should be from 1 to 10 , that is, if we dye 2 kilos we would have to use 20 liters of water.

- With this automated cloth stamping system, the integrity of the people working in this sector is preserved, since the risk of irritation due to direct contact with the dyes is avoided by not being in contact with the screen printing mixer.

\section{OBSERVATIONS}

In the stamping process it is important to regulate some parameters such as: the temperature and the time of stamping and the amount of dye that will be used according to the size of the image on the fabric and the color that is wanted.

The density of the paint influences the passage of the flow through the solenoid valve, because at higher density, the speed with which the fluid falls will be slower and in the same way if the paint is more liquid, the step of this will be at a higher speed.

There are different kinds of paints for dyeing in the textile industry. Within these, we have those that are reactive and direct. There are materials that do not absorb some types of dyes, such as synthetic materials that do not absorb the dye well and need a different treatment as more temperature.

The color that is given to the skeins of fabric will depend on the mixture that is made in the main container and, in addition, that the paint or dye is at the correct temperature so that it can absorb all the color and remain a uniform color in all the skein.

\section{RECOMMENDATIONS}

It is recommended to calibrate well the ultrasound sensor used in this project to obtain the required results.

The choice of material and the type of dye to be used must be quite rigorous, as this depends on an effective and correct result with respect to the stamping.

Regarding the issue of the color you want to give the fabrics, it is recommended to use PWM signals to control the work cycle of the engine.

\section{ACKNOWLEDGMENTS}

I thank my relatives who served as motivation to carry out this work and also a special thanks to the Ricardo Palma University for giving us the support and providing us with essential books for this work.

\section{REFERENCES}

[1] M. P. Groover, Fundamentals of Modern Manufacturing, McGraw Hill Interamenricana de México, 2007.

[2] J. M. G. de Durama. (February 2004). Automation of industrial processes University of the Basque Country. [Online]. Available: www.vc.ehu.es/depsi/jg/APIslides.pdf

[3] C. R. Cavaza, Ergonomics and productivity Editorial Limusa, 1991.

[4] B. G. Amanda, Textile Pattern Design, pp. 35-40, 2013.

[5] K. Ursula, Print of Fabrics, p. 7, 1972.

[6] V. D. Julia, Principles of Tintoreria, pp. 50-54, 2011

[7] J. Diaz and F. Muñoz, Comparison between a Fuzzy Controller and $a$ PID Controller for a Universal Motor, pp. 1, 2010.

[8] Soft Computing. [Online]. Available: http://www.esi.uclm.es/www/cglez/downloads/docencia/2011_Softco mputing/LogicaDifusa.pdf

[9] F. Brad, New Screenprint Guide, p. 7, 2005.

[10] L. Mejia "Design of a plan of improvements in the processes of weaving, dyeing and finishing of fabric in a textile company," pp. 20$21,2001$.

[11] L. A. J. Carlos, Electric Motors, p. 15, 2012.

[12] K Ramírez and M. Elvira, Manual of Dyeing and Artisan Fabric Printing, p. 5, 2006

[13] R. Canseco and J. Alberto, "Description of the technique of dyeing in wool with grana cochineal: Hacua an alternative production system of textile design in teotitlan del Valle, Oxaca," pp. 17-18, 2006.

[14] F. Ortiz and W. Y. Liu, Modeling and Control PD-Diffuse in Real Time for the Barar-Sphere System, pp. 1-2, 2004

[15] Material Didactico. [Online]. Available: http://www.dia.uned.es/ fmorilla/MaterialDidactico/El\%20controlado r\%20PID.pdf

[16] A. C. Soler, Pneumatics and Hydraulics, Barcelona -Spain: Marcombo S.A., 2007.

[17] Sector. Textil. Confecciones. Retomaria. Exportaciones. [Online]. Available: http://gestion.pe/economia/sector-textil-confeccionesretomaria-exportaciones-us-2000-millones-2015-2116526

[18] Newcastle. [Online]. Available: http://www.eng.newcastle.edu.au/ jhb519/teaching/caut1/Apuntes/PI D.pdf

[19] Camisetas. [Online]. Available: https://camisetas.com/blog/estampacion-de-camisetas-serigrafia/

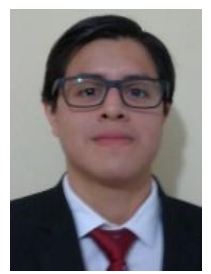

Juan José Encinas C. was born in Lima, Peru on December 9, 1997. He graduated from the private school "Trilce"; is studying the undergraduate degree in mechatronics engineering at the Ricardo Palma University. $\mathrm{He}$ is a member of the IEEE and participated in chapters such as EMBS and RAS. His areas of interest are robotics, biomedical, automation and unmanned aerial vehicles.

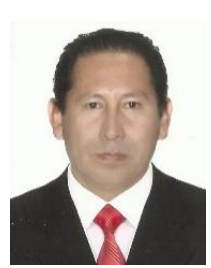

Mario Chauca was born in Ica, Peru. He was a past director in AOTS-Kenshu Kiokay del, Peru. He is a steering committee member of MWSCAS, and technical committee member of MWSCAS. He is a reviewer of the Journal named IRJPEH, and a chair session in ICIMA 2018. He obtained a scholarship AOTS-Japan, NIPA-Korea. He is a consultant in information and communication technologies in the government sector of Peru and in the United Nations Project-Inter-American Development Bank-Congress of the Republic of Peru and the Ministry of the Interior of Peru and in the private sector. He is a researcher registered by the Peruvian Government, adviser of the First General Award Project for more than 5000 projects in the contest from the Romero Group, adviser for first projects in Congress Intercon, Coneimera, and was nominated for the Graña y Montero Prize for Research in Peruvian Engineering. He has published as an author and advisor of articles published in IEEE xplore, Scopus. He teaches at the postgraduate and undergraduate level, with more than 25 years' experience. He graduated as an electronic engineer from Ricardo Palma University in Lima Peru. He obtained his master's degree and doctorate degree. 